\title{
THE HIGH VOLUME REUSE OF HYBRID BIOMASS ASH AS A PRIMARY BINDER IN CEMENTLESS MORTAR BLOCK
}

\author{
Cheah Chee Ban, Noor Shazea Ahmad Nordin, \\ Part Wei Ken, Mahyuddin Ramli and Kwan Wai Hoe \\ School of Housing, Building and Planning, Universiti Sains Malaysia, Georgetown, Malaysia
}

Received 2014-04-01; Revised 2014-04-16; Accepted 2014-05-29

\begin{abstract}
High Calcium Wood Ash (HCWA) and Pulverised Fuel Ash (PFA) are by-products from the wood biomass and coal energy production which are produced in large quantity with combined annual production of 500 million tonnes. This poses a serious problem for disposal of the waste material especially at places where land is scarce. The prescribed study was aimed to examine the mineralogical phases and their respective amount present in the industrial wastes which governs the hydration mechanism towards self-sustained solidification of the ashes when used in combination. Besides, the influence of various forming pressure and hydrothermal treatment temperature on mechanical strength performance of HCWA-PFA cementless mortar blocks was also examined. In the study, the mechanical strength of the HCWA-PFA cementless mortar block produced using various forming pressure and hydrothermal treatment temperature was assessed in terms of compressive strength and dynamic modulus. The results of the study are indicative that HCWA is rich in calcium oxide and potassium oxide content. This enables the hybridization of HCWA with the amorphous silica and alumina rich PFA to form a solid geopolymer binder matrix for fabrication of cementless mortar block. Throughout the study, dimensionally and mechanically stable HCWA-PFA geopolymer mortar blocks were successfully produced by press forming and hydrothermal treatment method. Based on statistical analysis, the hydrothermal treatment temperature has a statistically insignificant effect on the mechanical strength of the HCWA-PFA cementless mortar blocks. The dominant factor which governs the mechanical strength of the HCWA-PFA cementless mortar blocks was found to be the hydraulic forming pressure. Moreover, it was found that hybridized HCWA-PFA can be recycled as the sole binder for fabrication of cementless concrete block which is a useful construction material.
\end{abstract}

Keywords: Recycling, Waste Ash, Mechanical Properties, Cementless Concrete

\section{INTRODUCTION}

The burning of coal in coal power plant for electrical power production produces a substantial amount of coal fly ash and bottom ash as a combustion residue. The estimated annual worldwide production of Coal Fly Ash (CFA) in the year 2001 is 480 million tonne. The amount has been increasing since the last decade. The enormous amount of this waste material poses a serious solid waste management problem to the local authorities globally. On the other hand, a large portion of the wood ash from the wood biomass energy sector is land-filled covering Corresponding Author: Cheah Chee Ban, School of Housing, Building and Planning, Universiti Sains Malaysia, Georgetown, Malaysia
$70 \%$ of the total quantity produced, another $20 \%$ is used as soil supplement and the remnant $10 \%$ is used for miscellaneous application (Cheah and Ramli, 2011a). As wood ash consists of highly fine particulate matters which can be easily suspended in the air by action of wind, such method of disposal may result in subsequent problem such as respiratory health problem to residents dwelling near the disposal site of the ash material. Moreover, contamination of ground water resources can also be expected to occur by leaching of heavy metal contents of the ash by seepage of rain water (Udoeyo et al., 2006). Hence, the disposal of wood ash by mean of land369 
filling require a properly engineered land fill which have implication in term of disposal cost, hence, rendering such method of disposal uneconomical in long term. In view of that, a suitable method for large volume reuse of the industrial ashes is desired to ensure sustainable management of the coal and wood biomass ashes in the long term.

In the current advancement in material science, geopolymer binder is emerging to be a new class of concrete binder owing to the excellent properties exhibited by geopolymer such as good mechanical properties, good acid and sulfate resistance, low creep and shrinkage, environmental friendly and long term durability. With that, growing interests on the development of geopolymer binders as a possible alternative to cement binders for the applications in concrete industry has been observed for the last decade (Bakharev, 2005; Sata et al., 2012; Duxson et al., 2007; Boopathi et al., 2013). Geopolymers are usually produced by alkali activation of industrial aluminosilicate waste materials such as fly ash, Ground-Granulated Blast furnace Slag (GGBS) and rice husk ash. Under highly alkaline conditions with the presence of alkali hydroxide and silicate solution, polymerization takes place when reactive aluminosilicates are rapidly dissolved and free $\mathrm{SiO}_{4}$ and $\mathrm{AlO}_{4}$ tetrahedral units are released into the solution. The tetrahedral units are then cross linked to polymeric precursors by sharing oxygen atoms thus forming amorphous geopolymers (Komnitsas, 2011).

Brick is one of the most vital materials in construction industry. Fired clay based bricks are traditional and yet one of the most important masonry unit as a building material. The constituent materials which made up this type of bricks are a mixture of clay and cement. However, amidst ever growing environmental awareness regarding the energy consumption and $\mathrm{CO}_{2}$ emissions from the construction industry coupled with the emergence of geopolymer technology, cementless bricks based on the utilization of industrial by-products such as fly ash, wood ash, GGBS, rice husk ash and mine tailings have proven to be the current research trend in replacing clay based masonry unit in building industry (Raut et al., 2011; Turgut and Murat Algin, 2007; Ferone et al., 2011; Sukmak et al., 2013; Ahmari and Zhang, 2012; 2013; Morsy et al., 2012; Horsakulthai and Paopongpaiboon, 2013). One of the most common forming methods of brick fabrication is by hand-operated hydraulic press and the effect of various compaction pressures ranging from 600-5000 psi have been reported (El-Mahllawy, 2008; Freidin, 2007). Heat is one of the most governing factors in determining the strength of a geopolymer-based bricks as the condensation polymerization that takes place during the hardening process is endothermic in nature (Demie et al., 2013). Sukmak et al. (2013) examined the strength and microstructure properties of clay-fly ash geopolymer bricks under various curing conditions. It was concluded that the heat temperature is the main factor governing the microstructure and strength of clay-fly ash geopolymer bricks. While optimum temperature $\left(75^{\circ} \mathrm{C}\right)$ and curing duration $(48 \mathrm{~h})$ stimulate the geopolymerization reaction which resulted in strength enhancement with structural integrity, excessive temperature $\left(85^{\circ} \mathrm{C}\right)$ and heat duration $(72 \mathrm{~h})$ caused micro-cracks formation due to the loss of the pore fluid and hence reduction in strength.

Performance of alkali-activated cementless bricks in terms of compressive strength, flexural strength, Ultrasonic Pulse Velocity (UPV), water absorption and apparent density have been widely reported in the literatures (Freidin, 2007; Morsy et al., 2012; Turgut and Murat Algin, 2007; Ferone et al., 2011; Ahmari and Zhang, 2012). For instance, Ahmari and Zhang (2012) studied the effect of alkali activator concentration, water content, forming pressure and curing temperature on the compressive strength of geopolymer bricks based on copper mine tailings activated by sodium hydroxide solution. Compressive strength ranging from 3.69 to $33.7 \mathrm{MPa}$ was reported and the range was well-versed with almost all the ASTM strength requirement for bricks in different applications. Direct UPV measurement was performed by Turgut and Murat Algin (2007) on the brick sample fabricated form limestone dust and Wood Sawdust (WSW). They proposed that the WSW content, compressive and flexural strength value can be approximately determined using the non-destructive UPV test instead of destructive testing such as compression and flexure tests.

Recently, forestry and power plant waste namely High Calcium Wood Ash (HCWA) has found significant use as cement replacement material. Excellent mechanical and durability properties of HCWA as cement replacement material have been reported in a number of past literatures (Cheah and Ramli, 2013; 2012). Furthermore, significant amount of $\mathrm{K}_{2} \mathrm{O}$ was found in HCWA and is indicative that HCWA has a high level of alkalinity (Cheah and Ramli, 2011a) and is highly potential to be used together with an 
aluminosilicate material in geopolymerization reaction. However, the utilization of HCWA in the fabrication of construction bricks has not been explored. Therefore, the current study proposed an innovative approach in utilizing HCWA to fabricate cementless geopolymer bricks based on the hybridization of HCWA and ASTM class F fly ash without the addition of any external chemical activator.

The present work aims to study the feasibility of recycling High Calcium Wood Ash (HCWA) and Pulverized Fly Ash (PFA) for use as a primary binder in the fabrication of cementless concrete block for building construction. Specific objectives of the research were: (1) To assess the influence of various forming pressure and hydrothermal treatment temperature on the compressive strength properties of HCWA-PFA cementless mortar. (2) To study the influence of various forming pressure and hydrothermal treatment temperature on the dynamic modulus properties of HCWA-PFA cementless mortar.

\section{MATERIALS AND METHODS}

\subsection{Materials}

The materials used in the study are namely High Calcium Wood Ash (HCWA), Pulverized Fuel Ash (PFA) and washed river sand. The properties of the materials are discussed as follow.

\subsection{High Calcium Wood Ash (HCWA)}

The primary binder phase of the specimens consists of High Calcium Wood Ash (HCWA) and Pulverized Fly Ash (PFA). HCWA is a byproduct acquired from an industrial scale fully automatic boiler unit (commercially known as Bio-Turbomax industry. The wood biomasses used as fuel in the boiler were derived from local rubber wood species dominantly Hevea brasiliensis. The wood biomasses were incinerated under a self-sustained burning condition within an atmosphere with a turbulent air flow supplied by an in-built air pump unit. The temperature of incineration was maintained within the range of $800 \pm 10^{\circ} \mathrm{C}$. Raw wood ash extracted from the boiler unit was sieved through a laboratory sieve with an opening size of $150 \mu \mathrm{m}$ to remove large agglomerated ash particles and carbonaceous materials. Ash passing the $150 \mathrm{~mm}$ sieve was then ground in a ring mill until a fine mean particle diameter $\left(\mathrm{d}_{50}\right)$ of $8.39 \mu \mathrm{m}$ materials were attained.

\subsection{Pulverized Fuel Ash (PFA)}

The pulverized fly ash used in the study was sourced from YTL Berhad. It was observed that $\mathrm{SiO}_{2}, \mathrm{Al}_{2} \mathrm{O}_{3}$, $\mathrm{Fe}_{2} \mathrm{O}_{3}, \mathrm{CaO}$ and $\mathrm{MgO}$ are the major oxide compounds present in PFA which made up of 43.22, 17.61, 13.73, 11.28 and $5.94 \%$ respectively by total mass of PFA. Other compounds namely $\mathrm{K}_{2} \mathrm{O}, \mathrm{TiO}_{2}, \mathrm{P}_{2} \mathrm{O}_{5}$ and $\mathrm{MnO}$ are only present in minor composition. The high $\mathrm{SiO}_{2}$ content in PFA suggests that the fly ash is siliceous in nature. The amount of $\mathrm{CaO}$ presents in PFA also suggest that the ash is classified as ASTM class F fly ash $(<20 \% \mathrm{CaO})$ and is a pozzolanic material which requires an external source of $\mathrm{Ca}(\mathrm{OH})_{2}$ to develop mechanical properties associated with the formation of C-S-H. The compositional sum of essential pozzolanic oxides, namely, $\mathrm{SiO}_{2}, \mathrm{Al}_{2} \mathrm{O}_{3}$ and $\mathrm{Fe}_{2} \mathrm{O}_{3}$ was found to be $74.56 \%$ of the total mass of PFA which conformed to the $70 \%$ minimum limit set in ASTM C618 to be classified as ASTM class F fly ash.

The Loss On Ignition (LOI) of PFA was determined to be $1.80 \%$ which is well below the $5 \%$ limit specified in ASTM Standard C618. High carbon levels could be detrimental to the durability performance of concrete as the interactions of soluble ions in fly ash and the variability of carbon content can result in significant airentrainment problems in fresh concrete.

\subsection{Aggregate and Mixing Water}

Fine aggregate used were locally sourced quartzitic natural river sand in uncrushed form with specific gravity of 2.64 and maximum aggregate size of 4.75 $\mathrm{mm}$. Fine aggregates were washed to remove clay content and dried to saturated surface dry condition prior to use as constituent material in mortar mixes. Fine aggregates were graded in accordance to BS812: Part 102 and grading of fine aggregates used was in compliance with overall grading limits of BS 882 as shown in Fig. 1. Fineness modulus of the fine aggregates was determined to be 3.26. Potable water from local water supply network was used as mixing water for all mortar mixes produced.

\subsection{Material Proportion}

The binder to sand ratio was fixed at $1: 2.25$ as in accordance to related study (Cheah and Ramli, 2011b) where $80 \%$ of the binder was HCWA and the remaining $20 \%$ was PFA. Water to binder ratio was 0.45:1. Thus, the total weight of HCWA, PFA, sand and water per cubic meter were 481, 120, 1353 and $271 \mathrm{~kg}$, respectively. 


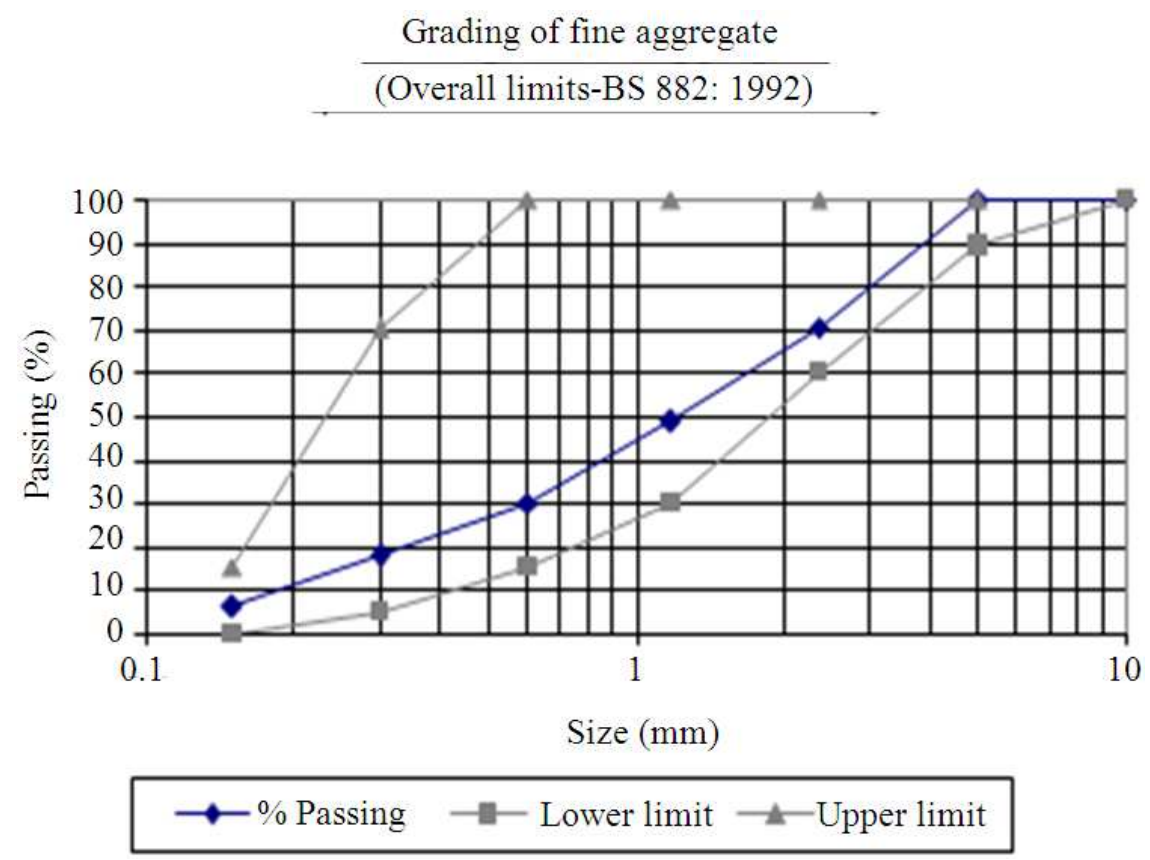

Fig. 1. Particle grading of fine aggregates

\subsection{Method}

The study was initiated with the fabrication of the test specimens by the method of pressure forming followed by subsequent hygrothermal curing of the test specimens in hot water bath. At the prescribed age of the test specimens, the mechanical performance of the hardened test specimens were evaluated using the compressive strength test, dynamic modulus test and ultrasonic pulse velocity test. Details of the various methods are described as follows.

\subsection{Fabrication of HCWA-PFA Cementless Mortar by Press Forming and Hydrothermal Treatment}

There were two independent variables in this experiment, i.e., forming pressure and hydrothermal treatment temperature. The forming pressure ranged from 6500 to 9500 psi, with a step increment of 1000 psi at every interval. Meanwhile, the hydrothermal treatment temperature was ranged from 60 to $100^{\circ} \mathrm{C}$, with $10^{\circ} \mathrm{C}$ at every level of increment.

Materials in dry state were mixed for 3 min using epicyclic mixer. Next, water was added and mixing process continued until uniformity was achieved. The mixture was then placed into BRE-pack Block Compressor and the aforementioned forming pressures were applied to form the blocks. The final dimensions for the block were $290 \times 140 \times 110 \mathrm{~mm}$. The blocks were then subjected to air curing for 7 days at ambient temperature of $25 \pm 2^{\circ} \mathrm{C}$ and relative humidity of $65 \pm 5 \%$. Subsequently, hydrothermal treatment was applied to the blocks for $24 \mathrm{~h}$ at different temperatures for each batch of specimens. The final step was to remove the specimens from hydrothermal treatment tank and allowed to cool down in air. Upon cooling, the test specimens were then subjected to various testing. Compressive and dynamic modulus tests were performed on the cooled specimens and the results were reported as the average of three test specimens.

\subsection{Compressive Strength Test, Dynamic Modulus of Elasticity and Ultrasonic Pulse Velocity Test}

For the mechanical performance evaluation, the HCWA-PFA cementless mortar blocks were examined for three parameters, namely, compressive strength, dynamic modulus of elasticity and ultrasonic pulse velocity. The cementless mortar blocks with edge dimensions of $290 \times 140 \times 90 \mathrm{~mm}$ were subjected to compression load up to failure using GOTECH GT 7001-BS300 servo hydraulic compression machine in accordance to procedures prescribed in BS EN 123903: 2009. For each forming condition, 3 blocks were 
tested and the average of the results obtained is reported as the representative compressive strength.

Meanwhile, the dynamic modulus of elasticity for the HCWA-PFA cementless mortar blocks was determined from the fundamental resonant frequency following the procedures described in the American Standard ASTM C215. The test was conducted by excitation in the longitudinal mode of vibration on the $140 \times 90 \mathrm{~mm}$ end face of a prism with a path length of $290 \mathrm{~mm}$.

\section{RESULTS}

The mechanical strength performance of the HCWA-PFA cementless concrete block is deliberated in terms of compressive strength and dynamic modulus of elasticity. The variation of the various mechanical strength performance parameters with the forming pressure and hydrothermal curing temperature is also discussed.

\subsection{Compressive Strength of HCWA-PFA Cementless Mortar Block}

The average compressive strengths of all specimens are shown in Fig. 2. The surface plot shows that the highest compressive strength could be achieved by applying 6500 psi to press the fresh mixture in order to form blocks, with $100^{\circ} \mathrm{C}$ hydrothermal treatment for $24 \mathrm{~h}$ at 7 days. The compressive strength was as high as $10.12 \mathrm{MPa}, 2.3$ times higher than the lowest specimens, which formed with forming pressure of $6500 \mathrm{psi}$ and $70^{\circ} \mathrm{C}$ for the hydrothermal treatment.

The surface plot shown in Fig. 2 also indicates that there is no specific trend of variation in the compressive strength with respect to the variation in the magnitude of forming pressure and hydrothermal treatment temperature. However, the three highest compressive strength of the HCWA-PFA cementless concrete block (along with their forming conditions) was found to be 10.12MPa $\left(6500 \mathrm{psi}, 100^{\circ} \mathrm{C}\right), 9.29 \mathrm{MPa}(9500 \mathrm{psi}$, $\left.90^{\circ} \mathrm{C}\right)$ and $8.78 \mathrm{MPa}\left(6500 \mathrm{psi}, 60^{\circ} \mathrm{C}\right)$.

\subsection{Analysis of Variance for Compressive Strength with Respect to Hydrothermal Curing Temperature and Forming Pressure}

The two-way ANOVA is presented in Fig. 3 and 4 illustrates the fitness of the data to the assumptions of model.

The residual plots for the response (compressive strength) illustrate the wellness of the data points fit in two-way ANOVA. Based on the normal probability plot, it is evident that the points are generally fit to the straight line, which indicates that the normality assumptions of the ANOVA model are valid.

With reference to Fig. 3, the two-way Analysis of Variance (ANOVA) shows that the variation of forming pressure has a significant effect on the compressive strength of the HCWA-DSF cementless mortar blocks formed as indicated by the $\mathrm{p}$ value which was found to be 0.000 which is less than 0.05 .

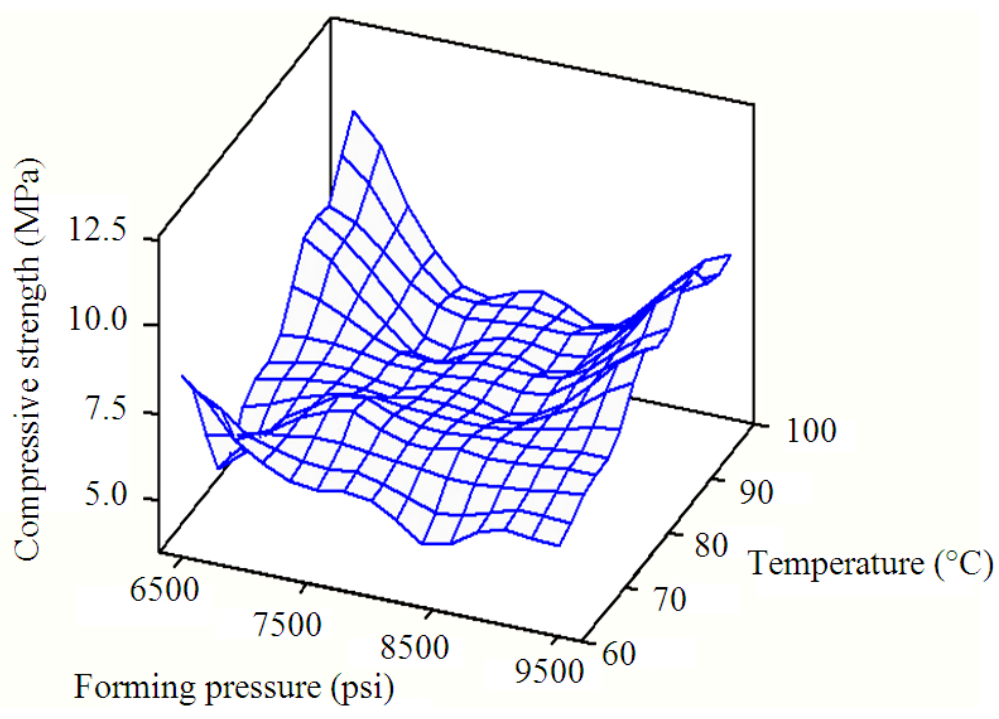

Fig. 2. Surface plot of compressive strength versus hydrothermal treatment temperature and forming pressure 
Cheah Chee Ban et al. / American Journal of Applied Sciences 11 (8): 1369-1378, 2014

Two-way ANOVA: Comp versus Temperature, Forming Pressure

$\begin{array}{lrrrrr}\text { Source } & \text { DF } & \text { SS } & \text { MS } & \text { F } & \text { P } \\ \text { Temperature } & 4 & 10.443 & 2.6108 & 1.19 & 0.322 \\ \text { Forming Pressure } & 3 & 62.410 & 20.8034 & 9.50 & 0.000 \\ \text { Error } & 72 & 157.702 & 2.1903 & & \\ \text { Total } & 79 & 230.555 & & & \\ & \\ \text { S }=1.480 \quad \text { R-Sq }=31.608 & \text { R-Sq }(\text { adj })=24.958\end{array}$
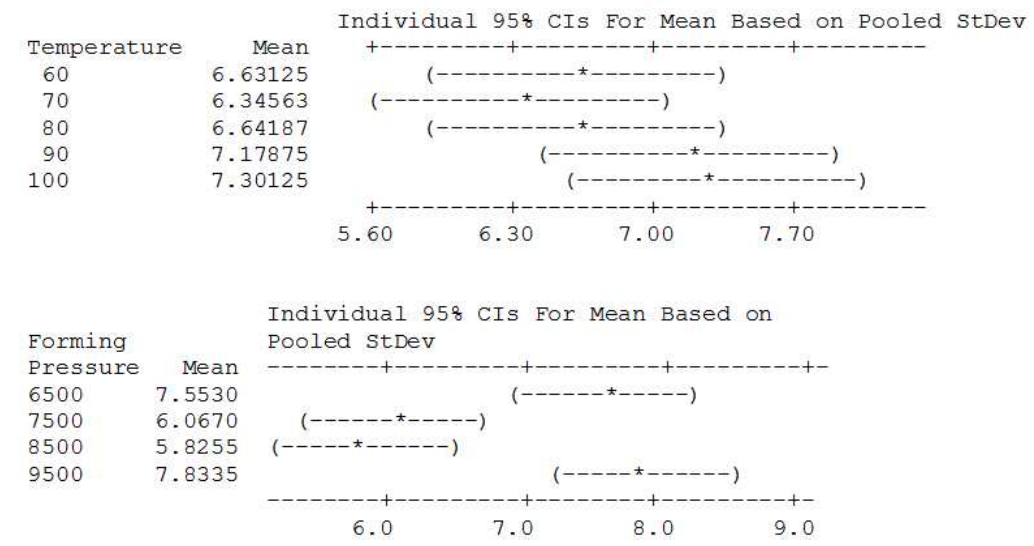

Fig. 3. Two-way ANOVA for compressive strength versus hydrothermal treatment temperature $\left({ }^{\circ} \mathrm{C}\right)$ and forming pressure (psi)

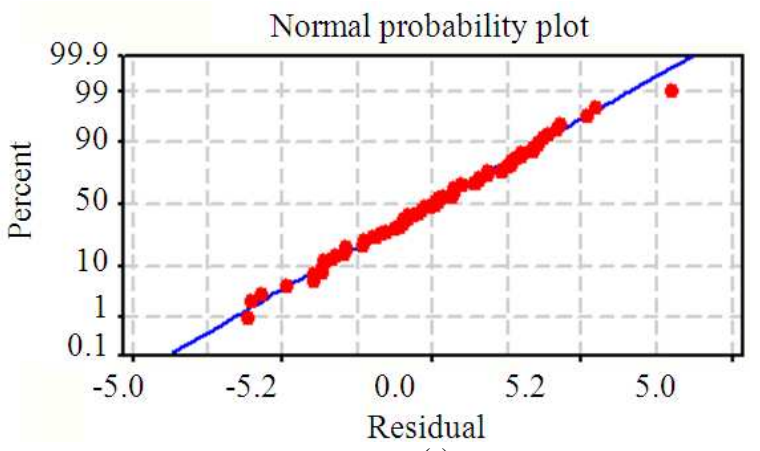

(a)

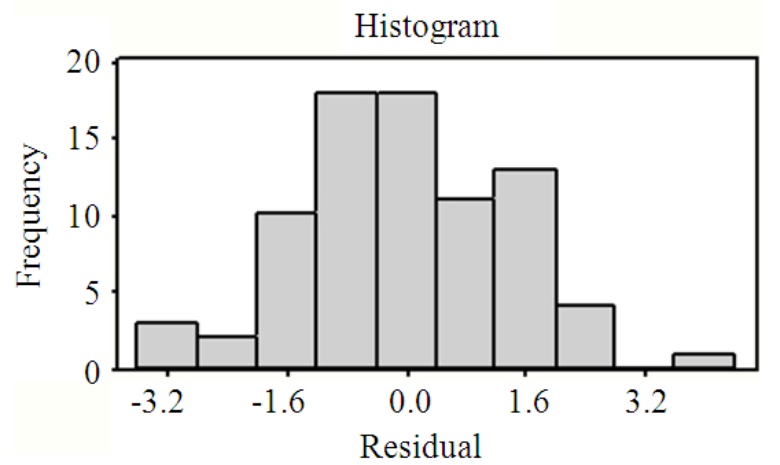

(c)

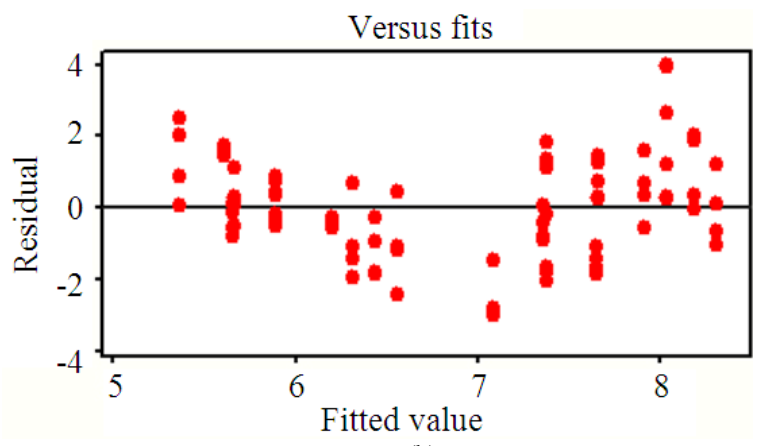

(b)

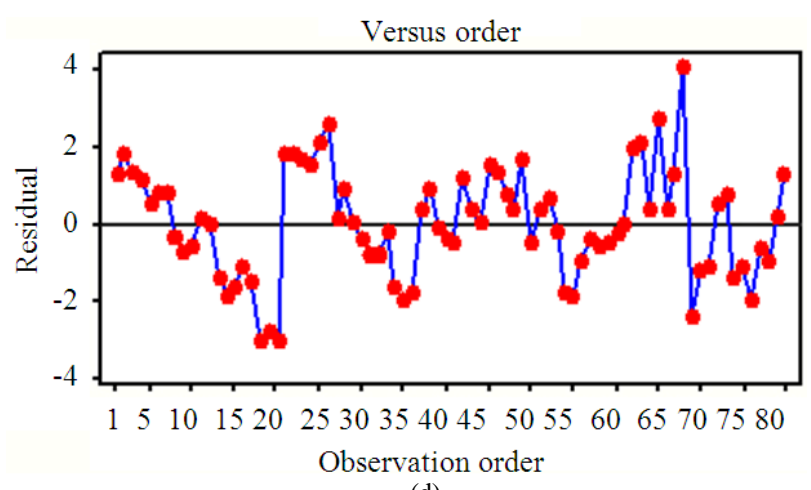

(d)

Fig. 4. Residual plots for compressive strength 


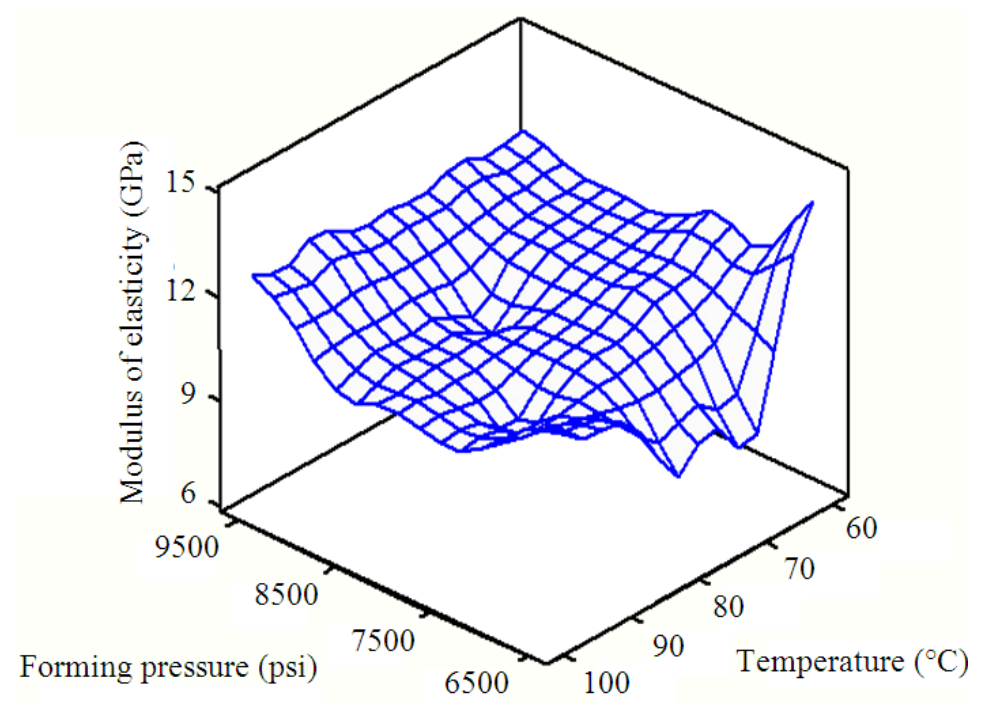

Fig. 5. Surface plot of average dynamic modulus of elas-ticity (GPa) versus hydrothermal temperature $\left({ }^{\circ} \mathrm{C}\right)$ and forming pressure (psi)

On the other hand, the output of two-way ANOVA indicated that the variation of the hydrothermal treatment temperature has no significant effect on the compressive strength of the HCWA-DSF cementless mortar blocks formed as indicated by the $p$ value which was found to be 0.322 which is more than 0.05 .

The aforementioned statistical analysis implies that the variation of hydrothermal treatment temperature from $60-100^{\circ} \mathrm{C}$ do not have a significant influence on the compressive strength of the HCWA-PFA cementless block produced. However, the variation on the forming pressure has a significant influence on the compressive strength of the cementless block produced. Forming pressure of 9500 psi was found to be the optimum pressure that produces HCWA-PFA mortar block with the highest average compressive strength. Nevertheless, the mean compressive strength at forming pressure of 6500 psi was $7.55 \mathrm{MPa}$, only $3.7 \%$ lower than the highest category, i.e., 9500 psi.

\subsection{Dynamic Modulus of Elasticity}

Figure 5 illustrates the surface plot of average dynamic modulus of elasticity versus hydrothermal temperature and forming pressure. The elastic modulus exhibited by the HCWA-PFA mortar blocks from under pressure of 9500 psi were relatively more stable, not sensitive to changes in treatment temperature. The value of elastic modulus was found to range between $12.35-12.80 \mathrm{GPa}$, with standard deviation of $0.17 \mathrm{GPa}$. The highest elastic modulus was attained by applying 6500 psi of forming pressure and $60^{\circ} \mathrm{C}$ of treatment temperature. The elastic modulus of the specimens formed under 6500 psi were fluctuated as the treatment temperature varies, having standard deviation of $2.53 \mathrm{GPa}$. For the HCWA-PFA mortar blocks formed at 7500 psi and 8500 psi less variation in the value of elastic modulus was observed when hydrothermal treatment temperature was varied from 60 to $100^{\circ} \mathrm{C}$. Their standard deviations were about $1.25 \mathrm{GPa}$ and $0.81 \mathrm{GPa}$ respectively.

\section{DISCUSSION}

The optimum forming pressure to achieve the best compressive strength performance of the HCWA-PFA mortar blocks is 6500psi. At the prescribed forming pressure, the fine particles of HCWA, fly ash and aggregate achieved its highest level of compaction, hence, leading to a strong cohesion and optimum binder paste-aggregate bonding within the geopolymer brick. Meanwhile, the optimum hydrothermal curing temperature is $60^{\circ} \mathrm{C}$. At the prescribed hydrothermal treatment temperature, the heat provided by the hydrothermal treatment is adequate to accelerate the dissolution of silica and alumina present in fly ash, promoting both the geopolymerization and pozzolanic reaction in the geopolymer concrete, hence, highest compressive strength could be achieved (Chen et al., 2011; Zhao et al., 2009). 
With reference to compressive strength properties, the HCWA-PFA cementless concrete block formed with the aforementioned pressure and temperature are qualified as Class I load bearing block as referred to the BS EN 771-1 classification system. In view of that, the most suitable forming pressure and hydrothermal treatment temperature for the most energy efficient fabrication of the load bearing blocks are $6500 \mathrm{psi}$ and $60^{\circ} \mathrm{C}$, respectively. Besides, all HCWA-PFA cementless mortar block produced in the study exhibited compressive strength of more than 5.20 MPa. This qualify them to be classified as load bearing bricks as defined by the compressive strength specification in BS EN 771-1.

From the economic point of view, higher forming pressure resulted in higher density brick, which increases the unit weight of the fabricated wall in building and this in turns restricted the floor height of building. Besides, a higher block density also caused an increase in transportation cost for the fabricated bricks. Moreover, a higher forming pressure used for block manufacturing also result in higher manufacturing energy consumption and also higher cost of maintenance of the hydraulic system. Hence, the recommended forming pressure to be used for large scale manufacturing of the HCWA-PFA cementless mortar block is 6500 psi. As for the hydrothermal treatment temperature, since it has no significant effect on the compressive strength, it is advisable to keep it to the lowest possible in order to save on the production cost. As the lower limit for the hydrothermal treatment temperature of the study was $60^{\circ} \mathrm{C}$, the recommended hydrothermal treatment temperature is $60^{\circ} \mathrm{C}$ based on the results of the study.

In order to be graded as Class I: Engineering Bricks in BS EN 771-Part 1, the compressive strength of the bricks must fall in the range of 7-12 MPa. With reference to the surface plot in Fig. 2, the most economic HCWA-PFA block forming process would be applying 6500 psi forming pressure followed by subsequent hydrothermal treatment at the temperature of $60^{\circ} \mathrm{C}$. Although increasing the hydrothermal treatment temperature to $100^{\circ} \mathrm{C}$ or forming pressure to 9500 psi would provide higher strengths, however they would still be categorized under the same classification as prescribed in BS EN 771-Part 1.

The dynamic modulus is considered approximately equal to the initial tangent modulus hence, appreciably higher than the static modulus which is determined by application of compression stress on the specimen
(Neville, 1996). Dynamic modulus is the ratio of stress to strain under vibratory conditions. It is a property of visco-elastic material such as cementitious composites. Dynamic modulus is closely related to the static modulus elasticity which is also influenced by the two primary parameters namely modulus elasticity of the aggregate and the bond strength between the binder matrix and the aggregate of a given cementitious matrix (Neville, 1996). Based on the results of the dynamic modulus, it is evident that the variation in the forming pressure and curing temperature has very little influence on the bond strength between the HCWA-PFA hybrid binder matrix and the aggregate.

\section{CONCLUSION}

Based on the observations and analysis of data acquired throughout the investigation, a number of major conclusions can be derived as follows.

HCWA, an industrial ash derived from combustion of rubber wood waste, which is rich in calcium hydroxide and potassium oxide can be hybridized with PFA which is rich in amorphous alumino-silicate compound to form a solid binder matrix for the fabrication of cementless mortar blocks. Statistical analysis implies that the variation of hydrothermal treatment temperature from $60-100^{\circ} \mathrm{C}$ do not have a significant influence on the compressive strength of the HCWA-PFA cementless block produced. However, the variation on the forming pressure has a significant influence on the compressive strength of the cementless block produced most likely due to variation of mix porosity with the varying forming pressure. All HCWA-PFA cementless mortar block formed are dimensionally stable and exhibited compressive strength of more than 5.20 MPa. This qualify them to be classified as load bearing bricks as defined by BS EN 771-1. The variation in the forming pressure and curing temperature has very little influence on the bond strength between the HCWA-PFA hybrid binder matrix and the aggregate. The variation of forming temperature and hydrothermal curing temperature has minimal effect on the quality of binder paste matrix. Hybridized HCWA-PFA can be recycled as the sole binder for fabrication of cementless concrete block which is a very useful construction material for building construction.

The current study is limited to the mechanical strength performance of the HCWA-PFA cementless block. Further study can be performed to study the durability performance of HCWA-PFA Cementless block. 


\section{ACKNOWLEDGEMENT}

The researchers would like to express their utmost gratitude to the Universiti Sains Malaysia and Ministry of Education for the financial support as well as to all parties that have contributed to this study.

\section{REFERENCES}

Ahmari, S. and L. Zhang, 2012. Production of ecofriendly bricks from copper mine tailings through geopolymerization. Construct. Build. Mater., 29: 323-331. DOI: 10.1016/j.conbuildmat.2011.10.048

Ahmari, S. and L. Zhang, 2013. Utilization of Cement Kiln Dust (CKD) to enhance mine tailings-based geopolymer bricks. Construct. Build. Mater., 40: 1002-1011.

DOI:

10.1016/j.conbuildmat.2012.11.069

Bakharev, T., 2005. Durability of geopolymer materials in sodium and magnesium sulfate solutions. Cement Concrete Res., 35: 1233-1246. DOI: 10.1016/j.cemconres.2004.09.002

Boopathi, M.M., K.P. Arulshri and N. Iyandurai, 2013. Evaluation of mechanical properties of aluminium alloy 2024 reinforced with silicon carbide and fly ash hybrid metal matrix composites. Am. J. Applied Sci., $\quad$ 10: 219-229. DOI: 10.3844/ajassp.2013.219.229

Cheah, C.B. and M. Ramli, 2011a. The implementation of wood waste ash as a partial cement replacement material in the production of structural grade concrete and mortar: An overview. Resources, Conserv. Recycl., 55: 669-685. DOI: 10.1016/j.resconrec.2011.02.002

Cheah, C.B. and M. Ramli, 2011b. Mechanical strength and durability of high performance mortar containing densified silica fume. Am. J. Applied Sci., 8 : $\quad 82-82$. $\quad$ DOI: $82-$ 91.10.3844/ajassp.2011.82.91

Cheah, C.B. and M. Ramli, 2012. Mechanical strength, durability and drying shrinkage of structural mortar containing HCWA as partial replacement of cement. Construct. Build. Mater., 30: 320-329. DOI: 10.1016/j.conbuildmat.2011.12.009

Cheah, C.B. and M. Ramli, 2013. The engineering properties of high performance concrete with HCWA-DSF supplementary binder. Construct. Build. Mater., 40: 93-103. DOI: 10.1016/j.conbuildmat.2012.10.010
Chen, Y., Y. Zhang, T. Chen, Y. Zhao and S. Bao et al., 2011. Preparation of eco-friendly construction bricks from hematite tailings. Construct. Build. Mater., 25: 2107-2111. DOI: 10.1016/j.conbuildmat.2010.11.025

Demie, S., M.F. Nuruddin and N. Shafiq, 2013. Effects of micro-structure characteristics of interfacial transition zone on the compressive strength of self-compacting geopolymer concrete. Construct. Build. Materi., 41: 91-98. DOI: 10.1016/j.conbuildmat.2012.11.067

Duxson, P., J.L. Provis, G.C. Lukey and J.S.J. Van Deventer, 2007. The role of inorganic polymer technology in the development of 'green concrete'. Cement Concrete Res., 37: 1590-1597. DOI: 10.1016/j.cemconres.2007.08.018

El-Mahllawy, M.S., 2008. Characteristics of acid resisting bricks made from quarry residues and waste steel slag. Construct. Build. Mater., 22: 1887-1896.

DOI: 10.1016/j.conbuildmat.2007.04.007

Ferone, C., F. Colangelo, R. Cioffi, F. Montagnaro and L. Santoro et al., 2011. Mechanical performances of weathered coal fly ash based geopolymer bricks. Proc. Eng., 21: 745-752. DOI: 10.1016/j.proeng.2011.11.2073

Freidin, C., 2007. Cementless pressed blocks from waste products of coal-firing power station. Construct. Build. Mater., 21: 12-18. DOI: 10.1016/j.conbuildmat.2005.08.002

Horsakulthai, V. and K. Paopongpaiboon, 2013. Strength, chloride permeability and corrosion of coarse fly ash concrete with bagasse-rice huskwood ash additive. Am. J. Applied Sci., 10: 239246. DOI: 10.3844/ajassp.2013.239.246

Komnitsas, K.A., 2011. Potential of geopolymer technology towards green buildings and sustainable cities. Proc. Eng., 21: 1023-1032. DOI: 10.1016/j.proeng.2011.11.2108

Morsy, M.S., S.H. Alsayed and Y.A. Salloum, 2012. Development of eco-friendly binder using metakaolin-fly ash-lime-anhydrous gypsum. Construct. Build. Mater., 35: 772-777. DOI: 10.1016/j.conbuildmat.2012.04.142

Neville, A.M., 1996. Properties of Concrete, Addison Wesley Longman. 1st Edn., Edinburgh, Essex, UK, ISBN-10: 978-0273755807, pp: 844. 
Raut, S.P., R.V. Ralegaonkar and S.A. Mandavgane, 2011. Development of sustainable construction material using industrial and agricultural solid waste: A review of waste-create bricks. Construct. Build. Mater., 25: 4037-4042. DOI: 10.1016/j.conbuildmat.2011.04.038

Sata, V., A. Sathonsaowaphak and P. Chindaprasirt, 2012. Resistance of lignite bottom ash geopolymer mortar to sulfate and sulfuric acid attack. Cement Concrete Compos., 34: 700-708. DOI: 10.1016/j.cemconcomp.2012.01.010

Sukmak, P., S. Horpibulsuk and S.L. Shen, 2013. Strength development in clay-fly ash geopolymer. Construct. Build. Mater., 40: 566-574. DOI: 10.1016/j.conbuildmat.2012.11.015
Turgut, P. and H. Murat Algin, 2007. Limestone dust and wood sawdust as brick material. Build. Environ., 42: 3399-3403. DOI: 10.1016/j.buildenv.2006.08.012

Udoeyo, F.F., H. Inyang, D.T. Young and E.E. Oparadu, 2006. Potential of wood waste ash as an additive in concrete. J. Materials Civil Eng., 18: 605-611. DOI: 10.1061/(ASCE)08991561(2006)18:4(605)

Zhao, F.Q., J. Zhao and H.J. Liu, 2009. Autoclaved brick from low-silicon tailings. Construct. Build. Mater., 23: 538-541. DOI: 10.1016/j.conbuildmat.2007.10.013 